\title{
Analisis Peramalan Kebutuhan Energi Listrik untuk Kabupaten Bireuen Menggunakan Perangkat Lunak LEAP
}

\author{
Devi Sutri Insani, Badriana, dan Muhammad Daud* \\ Jurusan Teknik Elektro, Fakultas Teknik, Universitas Malikussaleh \\ *Corresponding author, e-mail: mdaud@unimal.ac.id
}

\begin{abstract}
Abstrak - Meningkatnya konsumsi energi listrik suatu daerah karena berkembangnya perekonomian harus diantisipasi sedini mungkin agar energi listrik dapat tersedia dalam jumlah yang cukup dan harga yang terjangkau. Salah satu yang perlu dilakukan dalam mengantisipasi hal tersebut adalah peramalan kebutuhan energi listrik. Makalah ini bertujuan untuk memprediksi kebutuhan energi listrik menggunakan perangkat lunak Long-range Energy Alternatives Planning system (LEAP) dengan mengambil kasus pada Kabupaten Bireuen. Berdasarkan data-data historis sejak tahun 2012 berupa perkembangan penduduk, jumlah pelanggan, rasio elektrifikasi, intensitas energi, dan profil konsumsi energi listrik, maka dilakukan analisis untuk memprakirakan kebutuhan energi listrik di Kabupaten Bireuen untuk masa mendatang sampai dengan tahun 2026. Hasil analisis data meramalkan bahwa pada tahun 2026, jumlah pelanggan listrik akan mencapai 183.016 pelanggan dengan rata-rata pertumbuhan adalah 4,7 \% per tahun, dan konsumsi energi listrik akan mencapai 563,02 GWh dengan rata-rata pertumbuhan sebesar 10,67\% per tahun. Selain itu, diperoleh juga bahwa rasio elektrifikasi akan meningkat terus mencapai 99,42 \% pada tahun 2026 sedangkan elastisitas energi akan menurun terus mencapai angka 0,61 pada tahun tersebut.
\end{abstract}

Kata Kunci: energi listrik, kebutuhan energi listrik, rasio elektrifikasi, elastisitas energi, LEAP.

\begin{abstract}
Increasing electrical energy consumption in a region due to economic development must be anticipated as early as possible hence the electricity will be available sufficiently and at affordable prices. Therefore, forecasting electrical energy consumption is a crucial thing to be done. This paper aims to forecast electrical energy consumption in Bireuen District for 2026. The forecast was using Long-range Energy Alternatives Planning system (LEAP) software which based on historical data since 2012 in the form of population development, number of customers, electrification ratio, energy intensity, and profile of electrical energy consumption. The results predict that in 2026, electricity customers will reach 183,016 customers with an average growth of $4.7 \%$ per year, and electricity consumption will reach 563.02 GWh with an average growth of $10.67 \%$ per year. It was also obtained that the electrification ratio will continue to increase to $99.42 \%$ in 2026 while the energy elasticity will continue to decline to reach 0.61 in that year.
\end{abstract}

Keywords: electrical energy, electrical energy consumption, electrification ratio, energy elasticity, LEAP.

\section{Pendahuluan}

Perkembangan pembangunan berkelanjutan selalu diiringi dengan kemajuan teknologi dan kemajuan ekonomi serta peningkatan taraf hidup yang signikan. Kemajuan ini menyebabkan konsumsi energi listrik yang terus meningkat. Kondisi ini tentunya harus diantisipasi sedini mungkin agar penyediaan energi listrik dapat tersedia dalam jumlah yang cukup dan harga yang terjangkau.

Salah satu cara yang perlu ditempuh untuk mengantisipasi hal tersebut adalah dengan melakukan peramalan atau prakiraan (forecasting). Peramalan merupakan suatu usaha/kegiatan untuk memprediksi kondisi di masa yang akan datang. Pada sistem kelistrikan, strategi prakiraan juga sangat dibutuhkan untuk memprakirakan secara tepat seberapa besar kebutuhan energi listrik di masa mendatang. Prakiraan yang tidak tepat akan mengakibatkan tidak cukupnya energi listrik yang disalurkan ke masyarakat, sebaliknya jika prakiraan beban yang terlalu besar maka akan mengakibatkan kelebihan kapasitas energi sehingga menyebabkan kerugian. Dengan mengetahui prakiraan permintaan listrik, upaya yang harus dilakukan untuk memasok kebutuhan listrik dapat dilaksanakan secara efisien dan terencana. Oleh sebab itu, peramalan energi listrik sangatlah diperlukan. Adanya data perkembangan 
penduduk, rasio elektrifikasi, jumlah pelanggan, intensitas energi, serta profil konsumsi energi, maka dengan menggunakan perangkat lunak Long-range Energy Alternatives Planning system (LEAP) hal itu bisa diramalkan.

Terkait peramalan atau prakiraan energi listrik yang menggunakan LEAP ini, di antara penelitian yang pernah dilakukan adalah penelitian yang memproyeksikan kebutuhan dan penyediaan energi listrik di Jawa Tengah yang menyajikan hasil prakiraan berupa neraca komuditas litrik, konsumsi energi, dan produksi energi listrik [1]. Penelitian lain adalah analisa pertumbuhan beban terhadap ketersedian energi listrik di Sulawesi Selatan [2], yang menggunakan perangkat lunak LEAP untuk meramalkan konsumsi energi listrik, beban puncak, dan produksi energi listrik. Juga penelitian kajian perencanaan energi listrik di wilayah Kabupaten Sorong [3], yang juga menggunakan perangkat lunak LEAP serta membandingkannya dengan hasil perhitungan secara manual.

Beranjak dari penelitian-penelitian tersebut, maka penelitian ini bertujuan menganalisis data menggunakan perangkat lunak LEAP untuk meramalkan kebutuhan energi listrik pada Kabupaten Bireuen di Provinsi Aceh. Kabupaten Bireuen merupakan sebuah kabupaten dengan luas daerah sebesar 1.796,32 $\mathrm{km}^{2}$ dan jumlah penduduk sebanyak 453.224 jiwa, dan merupakan sebuah daerah yang berkembang maju dengan signifikan khususnya di bidang perdagangan dan pemerintahan [4]. Hal ini mendorong penulis untuk menjadikan Kabupaten Bireuen sebagai obyek penelitian ini.

Penyediaan energi listrik untuk wilayah Kabupaten Bireuen selama ini disuplai oleh PT PLN melalui jaringan transmisi dengan kapasitas satu gardu induk yang berlokasi di Desa Juli km 7 . Gardu induk Bireuen ini memiliki dua trafo daya dengan kapasitas masing-masing 60 MVA dan terdiri dari 10 penyulang. Dari gardu induk ini daya disalurkan ke empat gardu hubung yaitu gardu hubung Samalanga, gardu hubung Bireuen, Gardu Hubung Matang, dan gardu hubung Gerugok yang diteruskan dengan jaringan distribusi untuk melayani para pelanggan.

Adapun prakiraan atau peramalan energi listrik dalam studi ini didasarkan pada analisis data tahun 2012 - 2016 untuk memperoleh proyeksi jumlah pelanggan listrik, konsumsi energi listrik, rasio elektrifikasi, dan elastistas energi pada tahun 2017 - 2026.

\section{Perencanaan dan Peramalan Kebutuhan Energi Listrik}

Suatu perencanaan dibuat agar dapat membantu dalam memilih alternatif yang paling baik dan efisien. Perencanaan ketenagalistrikan di Indonesia dilakukan dalam lingkup nasional maupun daerah. Perencanaan ketenagalistrikan seperti yang dicantumkan dalam Undang-Undang nomor 30 tahun 2009, merupakan kewajiban bagi penyelenggara pemerintahan yaitu pemerintah pusat dan pemerintah daerah. Rencana kebijakan bidang ketenagalistrikan dirumuskan dalam Rencana Umum Ketenagalistrikan Nasional (RUKN) dan Rencana Umum Ketenagalistrikan Daerah (RUKD). RUKN dan RUKD harus selaras antar keduanya. Oleh karena itu, penyusunan RUKD harus mempertimbangkan RUKN dan disusun sesuai pedoman yang dikeluarkan oleh Pemerintah [5].

Penggunaan tenaga listrik diperkirakan akan selalu meningkat setiap tahunnya. Hal ini dikarenakan semakin berkembangnya kebutuhan masyarakat yang harus dipenuhi. Banyak faktor yang berpengaruh terhadap tingkat kebutuhan tenaga listrik, seperti faktor ekonomi, kependudukan, kewilayahan, perencanaan pembangunan daerah, dan lain-lain [6].

Kebutuhan tenaga listrik suatu daerah bergantung pada letak daerah, jumlah penduduk, standar kehidupan, rencana pembangunan atau pengembangan daerah di masa yang akan datang. Strategi prakiraan kebutuhan energi listrik sangat dibutuhkan agar dapat memprakirakan dengan tepat seberapa besar daya listrik yang dibutuhkan untuk melayani beban dan kebutuhan energi dalam sistem distribusi energi listrik. Pembagian kelompok peramalan beban terdiri atas peramalan jangka pendek, peramalan jangka menengah, dan peramalan jangka panjang [2].

\subsection{Metode Pendekatan Perencanaan Energi}

Ada berbagai metode pendekatan untuk melakukan prakiraan kebutuhan energi listrik, diantaranya pendekatan ekonometri, pendekatan proses, pendekatan time series, pendekatan enduse, dan pendekatan trend. Dari beberapa metode pendekatan tersebut, yang paling sering digunakan sebagai pendekatan untuk proyeksi kebutuhan energi listrik adalah metode pendekatan ekonometri dan pendekatan end-use [2].

Penelitian ini menggunakan metode 
pendekatan end-use yang juga dikenal sebagai pendekatan engineering model. Pendekatan ini akan lebih detail walaupun secara perhitungan menggunakan fungsi yang lebih sederhana. Pertimbangan teknologi yang digunakan dalam proses aliran energi juga menjadi variabel perhitungan.

Lebih lanjut, pendekatan end-use dapat diuraikan sebagai berikut. Permintaan energi dari masing-masing kegiatan merupakan produk dari dua faktor, yaitu tingkat aktivitas (layanan energi) dan intensitas energi (penggunaan energi per unit layanan energi). Selain itu, permintaan total maupun permintaan energi sektoral dipengaruhi oleh rincian kegiatan yang berbeda yang membentuk komposisi atau struktur permintaan energi. Secara matematis pendekatan end-use dapat dirumuskan sebagai berikut [1], [2], [3]:

$$
E C=\sum_{i=1}^{i=n} Q_{i} I_{i}
$$

Dimana $E C$ adalah total konsumsi energi (energy consumption), $Q_{i}$ adalah jumlah dari layanan energi $i$, dan $I_{i}$ adalah intensitas penggunaan energi untuk layanan energi $i$.

Adapun layanan energi untuk masing-masing sektor pelanggan dapat dinyatakan dalam rumusrumus sebagai berikut [1], [2], [3]:

\section{a). Sektor rumah tangga}

Jumlah pelanggan (number of customer) sektor rumah tangga dinyatakan oleh

$$
N C_{H(t)}=N C_{H(t-1)}\left(1+\frac{C F_{H} \times g_{E}}{100}\right)
$$

Dimana $N C_{H(t)}$ adalah jumlah pelanggan sektor rumah tangga tahun $t, N C_{H(t-1)}$ adalah jumlah pelanggan sektor rumah tangga tahun sebelumnya, $C F_{H}$ adalah faktor kapasitas pelanggan sektor rumah tangga (yaitu rasio pertumbuhan pelanggan rumah tangga terhadap pertumbuhan pelanggan rumah tangga sebagai referensi), dan $g_{E}$ adalah pertumbuhan pelanggan sektor rumah tangga total.

Sedangkan konsumsi energi (energy consumption) sektor rumah tangga dinyatakan oleh

$$
\begin{aligned}
E C_{H(t)}= & E C_{H(t-1)}\left(1+\frac{e_{H} \times g_{E}}{100}\right) \\
& +I E_{H(t)}\left(N C_{H(t)}-N C_{H(t-1)}\right)
\end{aligned}
$$

Dimana $E C_{H(t)}$ adalah konsumsi energi sektor rumah tangga tahun $t, E C_{H(t-l)}$ adalah konsumsi energi listrik sektor rumah tangga tahun sebelumnya, $e_{H}$ adalah elastisitas konsumsi energi sektor rumah tangga tahun sebelumnya (yaitu rasio pertumbuhan permintaan energi sektor rumah tangga terhadap pertumbuhan ekonomi total), $g_{E}$ adalah pertumbuhan pelanggan sektor rumah tangga total, $I E_{H(t)}$ adalah intensitas energi rumah tangga baru tahun $t, N C_{H(t)}$ adalah jumlah pelanggan sektor rumah tangga tahun $t, N C_{H(t-1)}$ adalah jumlah pelanggan sektor rumah tangga tahun sebelumnya.

\section{b). Sektor bisnis}

Jumlah pelanggan (number of customer) sektor bisnis dinyatakan oleh

$$
N C_{B(t)}=N C_{B(t-1)}\left(1+\frac{C F_{B} \times g_{B}}{100}\right)
$$

Dimana $N C_{B(t)}$ adalah jumlah pelanggan sektor bisnis tahun $t, N C_{B(t-1)}$ adalah jumlah pelanggan sektor bisnis tahun sebelumnya, $C F_{B}$ adalah faktor kapasitas pelanggan sektor bisnis (yaitu rasio pertumbuhan pelanggan bisnis terhadap pertumbuhan pelanggan rumah tangga sebagai referensi), dan $g_{B}$ adalah pertumbuhan pelanggan sektor bisnis total.

Sedangkan konsumsi energi (energy consumption) sektor bisnis dinyatakan oleh

$$
E C_{B(t)}=E C_{B(t-1)}\left(1+\frac{e_{B} \times g_{B}}{100}\right)
$$

Dimana $E C_{B(t)}$ adalah konsumsi energi sektor bisnis tahun $t, E C_{B(t-1)}$ adalah konsumsi energi listrik sektor bisnis tahun sebelumnya, $e_{B}$ adalah elastisitas konsumsi energi sektor bisnis tahun sebelumnya (yaitu rasio pertumbuhan permintaan energi sektor bisnis terhadap pertumbuhan ekonomi total), $g_{B}$ adalah pertumbuhan pelanggan sektor bisnis total.

\section{c). Sektor industri}

Jumlah pelanggan (number of customer) sektor industri dinyatakan oleh

$$
N C_{I(t)}=N C_{I(t-1)}\left(1+\frac{C F_{I} \times g_{I}}{100}\right)
$$

Dimana $N C_{I(t)}$ adalah jumlah pelanggan sektor industri tahun $t, N C_{I(t-1)}$ adalah jumlah pelanggan sektor industri tahun sebelumnya, $C F_{I}$ adalah faktor kapasitas pelanggan sektor industri (yaitu rasio pertumbuhan pelanggan industri terhadap pertumbuhan pelanggan rumah tangga sebagai 
referensi), dan $g_{I}$ adalah pertumbuhan pelanggan sektor industri total.

Sedangkan konsumsi energi (energy consumption) sektor industri dinyatakan oleh

$$
E C_{I(t)}=E C_{I(t-1)}\left(1+\frac{e_{I} \times g_{I}}{100}\right)
$$

Dimana $E C_{I(t)}$ adalah konsumsi energi sektor industri tahun $t, E C_{I(t-1)}$ adalah konsumsi energi listrik sektor industri tahun sebelumnya, $e_{I}$ adalah elastisitas konsumsi energi sektor industri tahun sebelumnya (yaitu rasio pertumbuhan permintaan energi sektor industri terhadap pertumbuhan ekonomi total), $g_{I}$ adalah pertumbuhan pelanggan sektor industri total.

\section{d). Sektor publik}

Jumlah pelanggan (number of customer) sektor publik dinyatakan oleh

$$
N C_{P(t)}=N C_{P(t-1)}\left(1+\frac{C F_{P} \times g_{P}}{100}\right)
$$

Dimana $N C_{P(t)}$ adalah jumlah pelanggan sektor publik tahun $t, N C_{P(t-l)}$ adalah jumlah pelanggan sektor publik tahun sebelumnya, $C F_{P}$ adalah faktor kapasitas pelanggan sektor publik (yaitu rasio pertumbuhan pelanggan publik terhadap pertumbuhan pelanggan rumah tangga sebagai referensi), dan $g_{P}$ adalah pertumbuhan pelanggan sektor publik total.

Sedangkan konsumsi energi (energy consumption) sektor publik dinyatakan oleh

$$
E C_{P(t)}=E C_{P(t-1)}\left(1+\frac{e_{P} \times g_{P}}{100}\right)
$$

Dimana $E C_{P(t)}$ adalah konsumsi energi sektor publik tahun $t, E C_{P(t-I)}$ adalah konsumsi energi listrik sektor publik tahun sebelumnya, $e_{P}$ adalah elastisitas konsumsi energi sektor publik tahun sebelumnya (yaitu rasio pertumbuhan permintaan energi sektor publik terhadap pertumbuhan ekonomi total), $g_{P}$ adalah pertumbuhan pelanggan sektor publik total.

\subsection{Perangkat Lunak LEAP}

Pada penelitian ini data yang diperoleh diolah menggunakan perangkat lunak untuk mendapatkan hasil yang dibutuhkan. Perangkat lunak yang digunakan adalah Long-range Energy Alternatives Planning System (LEAP). LEAP adalah perangkat lunak yang dapat digunakan untuk melakukan analisis dan evaluasi kebijakan dan perencanaan energi. Perangkat lunak LEAP dikembangkan oleh Stockholm Environment Institute, yang berkantor pusat di Boston, Amerika Serikat. Versi pertama LEAP diluncurkan tahun 1981. Versi LEAP yang berbasis Windows baru dirilis pada tahun 2000 [7].

LEAP bekerja berdasarkan asumsi skenario yang diinginkan pengguna. Skenario tersebut dapat didasarkan pada perhitungan dari proses konversi bahan bakar menjadi energi hingga energi tersebut dikonsumsi masyarakat. LEAP menggunakan model pendekatan yang mempertimbangkan penggunaan akhir energi (pendekatan end-use). LEAP mendukung untuk proyeksi permintaan energi akhir maupun permintaan pada energi yang sedang digunakan secara detail termasuk cadangan energi, transportasi, dan lain sebagainya. Dengan LEAP, pengguna dapat melakukan analisa secara cepat dari sebuah ide kebijakan energi ke sebuah analisa hasil dari kebijakan tersebut. Hal ini dikarenakan LEAP mampu berfungsi sebagai database, sebagai sebuah alat peramal (forecasting tool), dan sebagai alat analisa terhadap kebijakan energi. Dalam perangkat lunak LEAP disediakan empat modul utama, yaitu modul variabel penggerak (driver variable module), modul permintaan (demand module), modul transformasi (transformation module), dan modul sumber daya energi (resources module) [7]. Gambar 1 menunjukkan tampilan perangkat lunat LEAP.

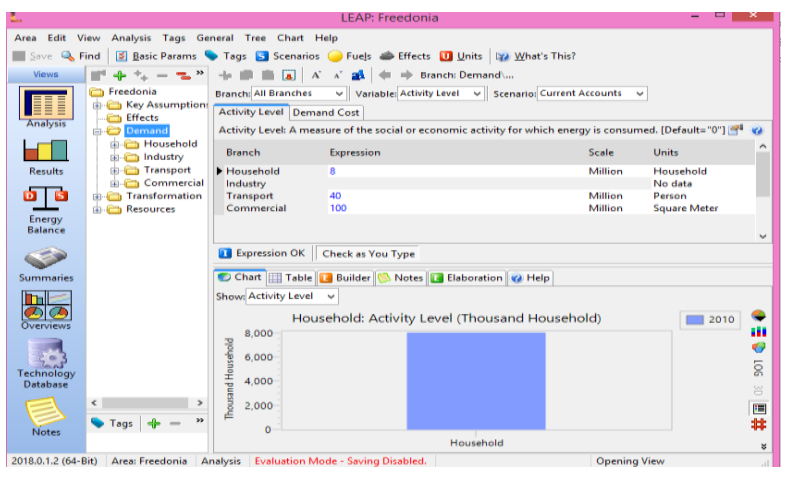

Gambar 1. Tampilan perangkat lunak LEAP

\section{Metode Penelitian}

\subsection{Tahapan-Tahapan Penelitian}

Penelitian ini terdiri dari beberapa tahapan, yaitu penyusunan rancangan penelitian, pengumpulan data, pengolahan data, perancangan model sistem analisis pada LEAP, input data dan analisis data menggunakan LEAP, penyajian hasil analisis data, dan penarikan kesimpulan. 
Penyusunan rancangan penyusunan berisi langkah-langkah memilih pendekatan metode analisis atau peramalan yang akan digunakan, merancang model analisis data, menentukan variabel-variabel penelitian yang akan diteliti, dan mentabulasi data-data yang diperlukan.

Variabel penelitian yang akan diteliti berupa variabel-variabel input bagi sistem analisis (peramalan) LEAP dan variabel-variabel output dari analisis. Variabel input terdiri empat variabel, yaitu jumlah pelanggan masa lalu, rasio elektrifikasi masa lalu, intensitas energi, dan produk domestik regional bruto (PDRB). Sedangkan variabel output juga terdiri empat variabel yaitu jumlah konsumsi energi, jumlah pelanggan, rasio elektrifikasi, dan elastisitas energi listrik masa depan.

Rasio elektrifikasi adalah perbandingan jumlah rumah tangga yang sudah tersedia energi listrik dalam suatu daerah terhadap total rumah tangga dalam daerah tersebut [8], [9]. Dengan demikian berarti semakin tinggi rasio elektrifikasi maka semakin merata penyediaan energi listrik untuk masyarakat dalam daerah tersebut.

Adapun elastisitas energi listrik adalah perbandingan antara pertumbuhan konsumsi energi listrik dengan pertumbuhan ekonomi. Nilai elastisitas energi ini menyatakan perubahan persentase penggunaan energi terkait dengan perubahan satu persen dalam aktivitas ekonomi atau produk domestik bruto [10], [11]. Dengan kata lain, elastisitas energi menyatakan persentase dalam konsumsi energi untuk mencapai satu persen perubahan dalam produk domestik bruto [12]. Ini berarti semakin kecil nilai elastisitas energi maka semakin efisien pemanfaatan energi listrik.

Untuk itu, maka tahapan penelitian berikutnya yakni pengumpulan data dimaksudkan untuk mengumpulkan data-data untuk memenuhi keperluan variabel-variabel input tersebut untuk dianilisis menggunakan LEAP agar diperoleh variabel-variabel output.

\subsection{Pengumpulan Data}

Pengumpulan data dilakukan dengan cara mengumpulkan data sekunder dari pihak pemilik/pengumpul data data primer yang terkait yaitu PT PLN (Persero) Area Bireuen dan BPS Kabupaten Bireuen. Data-data yang diperoleh dari kedua instansi tersebut, setelah dipilah dan disusun sesuai sektor pemakai maka disajikan tabel-tabel berikut ini. Data konsumsi energi listrik untuk setiap sektor pemakai dari tahun 2012 sampai dengan 2016 yang diperoleh dari PT PLN adalah sebagaimana tercantum pada Tabel 1. Adapun data jumlah pelanggan energi listrik untuk setiap sektor pemakai dari tahun 2012 sampai dengan 2016 yang juga diperoleh dari PT PLN adalah seperti disajikan pada Tabel 2.

Tabel 1. Konsumsi Energi Listrik Kab. Bireuen

\begin{tabular}{|c|c|c|c|c|c|}
\hline \multirow{2}{*}{ Sektor } & \multicolumn{5}{|c|}{ Konsumsi energi listrik (GWh) } \\
\hline & 2012 & 2013 & 2014 & 2015 & 2016 \\
\hline $\begin{array}{l}\text { Rumah } \\
\text { tangga }\end{array}$ & 89,70 & 93,70 & 101,33 & 111,07 & 123,76 \\
\hline Sosial & 7,14 & 7,81 & 8,09 & 9,88 & 11,96 \\
\hline Bisnis & 16,15 & 16,89 & 25,53 & 28,11 & 29,61 \\
\hline Industri & 15,87 & 17,15 & 19,68 & 21,79 & 23,73 \\
\hline Publik & 15,26 & 15,75 & 15,91 & 16,49 & 18,19 \\
\hline Total & 137,08 & 143,69 & 163,33 & 187,34 & 207,25 \\
\hline
\end{tabular}

Tabel 2. Jumlah Pelanggan Listrik Kab. Bireuen

\begin{tabular}{crrrrr}
\hline \multirow{2}{*}{ Sektor } & \multicolumn{5}{c}{ Jumlah pelanggan } \\
\cline { 2 - 6 } & \multicolumn{1}{c}{2012} & \multicolumn{1}{c}{2013} & \multicolumn{1}{c}{2014} & \multicolumn{1}{c}{2015} & \multicolumn{1}{c}{2016} \\
\hline Rumah & & & & \\
tangga & 87.684 & 91.023 & 94.237 & 97.929 & 101.210 \\
Sosial & 2.512 & 2.611 & 2.724 & 2.870 & 3.027 \\
Bisnis & 6.626 & 7.124 & 7.850 & 8.354 & 9.324 \\
Industri & 296 & 343 & 451 & 629 & 807 \\
Publik & 310 & 339 & 358 & 382 & 460 \\
\hline Total & 97.428 & 101.440 & 105.620 & 110.164 & 114.828 \\
\hline
\end{tabular}

Sementara itu data kependudukan beserta rasio elektrifikasi Kabupaten Bireuen dari tahun 2012 sampai dengan 2016 adalah sebagaimana disajikan dalam Tabel 3. Sedangkan data produk domestik regional bruto (PDRB) Kabupaten Bireuen dari tahun 2012 sampai dengan 2016 yang diperoleh dari BPS [4] adalah seperti disajikan dalam Tabel 4.

Tabel 3. Data Kependudukan dan Rasio Elektrifikasi Kab. Bireuen

\begin{tabular}{cccccc}
\hline Tahun & 2012 & 2013 & 2014 & 2015 & 2016 \\
\hline $\begin{array}{c}\text { Jumlah } \\
\text { penduduk }\end{array}$ & 406.083 & 413.817 & 423,397 & 435.300 & 443.627 \\
$\begin{array}{c}\text { Jumlah rumah } \\
\text { tangga }\end{array}$ & 93.818 & 95.779 & 97.818 & 100.505 & 102.428 \\
$\begin{array}{c}\text { Jumlah pelanggan } \\
\text { rumah tangga } \\
\quad \text { Rasio }\end{array}$ & 87.684 & 91.023 & 94.237 & 97.929 & 101.210 \\
$\begin{array}{c}\text { elektrifikasi (\%) } \\
\text { ela }\end{array}$ & 93,46 & 95,03 & 96,34 & 97,44 & 98,81 \\
\hline
\end{tabular}

Tabel 4. Data PDRB Kabupaten Bireuen Menurut Harga Berlaku 


\begin{tabular}{lrrrrr}
\hline & \multicolumn{1}{c}{2012} & \multicolumn{1}{c}{2013} & \multicolumn{1}{c}{2014} & \multicolumn{1}{c}{2015} & \multicolumn{1}{c}{2016} \\
\hline Pertanian & $2.813 .134,8$ & $3.035 .301,9$ & $3.174 .748,4$ & $3.447 .123,7$ & $3.645 .117,5$ \\
Pertambangan & $226.280,8$ & $238.149,9$ & $259.019,0$ & $272.471,5$ & $283.740,0$ \\
Industri pengolahan & $137.353,5$ & $147.992,2$ & $163.042,7$ & $171.521,2$ & $179.996,2$ \\
Listrik, gas, dan air & $7.572,6$ & $8.425,4$ & $9.581,5$ & $10.813,9$ & $12.760,1$ \\
Bangunan & $721.401,0$ & $769.698,5$ & $800.513,6$ & $857.204,5$ & $938.910,5$ \\
Perdagangan & $1.877 .112,6$ & $1.975 .958,2$ & $2.079 .046,6$ & $2.224 .594,6$ & $2.391 .898,4$ \\
Angkutan dan komunikasi & $1.156 .100,3$ & $1.263 .611,2$ & $1.328 .983,3$ & $1.367 .428,1$ & $1.400 .092,2$ \\
Lembaga keuangan & $345.444,6$ & $362.229,3$ & $383.756,4$ & $410.868,4$ & $452.885,2$ \\
Jasa-jasa & $960.729,4$ & $1.076 .964,4$ & $1.193 .618,8$ & $1.309 .987,5$ & $1.444 .762,5$ \\
\hline \multicolumn{1}{c}{ PDRB Total } & $8.245 .129,6$ & $8.878 .331,0$ & $9.392 .310,3$ & $10.072 .013,4$ & $10.750 .162,6$ \\
\hline \multicolumn{1}{c}{} \\
\hline
\end{tabular}

\subsection{Pengolahan Data}

Data yang diperoleh dari PT PLN wilayah Bireuen masih berupa data mentah yakni data pelanggan dan konsumsi energi listrik tiap sektor tarif dengan periode waktu per bulan. Skema tarif dibagi kedalam lima sektor, yaitu sektor sosial, sektor rumah tangga, sektor bisnis, sektor industri, dan sektor publik.

Adapun untuk analisis data menggunakan LEAP, di samping data jumlah pelanggan, dan konsumsi energi listrik, diperlukan juga data rasio elektrifikasi, pertumbuhan jumlah pelanggan, PDRB, serta intensitas energi listrik dan pertumbuhannya. Sehingga perlu dilakukan pengolahan data awal atau normalisasi untuk memperoleh data pertumbuhan jumlah pelanggan, intensitas energi, dan pertumbuhan intensitas energi tersebut. Pertumbuhan jumlah pelanggan merupakan persentase selisih jumlah pelanggan tahun $t$ dengan jumlah pelanggan tahun $t-1$ terhadap jumlah pelanggan tahun $t-1$. Intensitas energi didapat dari jumlah konsumsi energi pada Tabel 1 dibagi dengan jumlah pelanggan pada Tabel 2. Sedangkan pertumbuhan intensitas energi merupakan persentase selisih intensitas energi tahun $t$ dengan intensitas energi tahun $t-1$ terhadap intensitas energi tahun $t-1$.

Data-data hasil pengolahan awal tersebut disajikan sebagai berikut. Data pertumbuhan jumlah pelanggan dalam Tabel 5, intensitas energi listrik dalam Tabel 6, dan pertumbuhan intensitas energi dalam Tabel 7. Intensitas energi listrik menyatakan kepadatan penggunaan energi listrik, yaitu jumlah konsumsi energi masing-masing sektor pelanggan dibagi dengan jumlah pelanggan listrik sektor tersebut.

Tabel 5. Pertumbuhan Jumlah Pelanggan

\begin{tabular}{|c|c|c|c|c|c|}
\hline \multirow{2}{*}{ Sektor } & \multicolumn{4}{|c|}{ Pertumbuhan jumlah pelanggan (\%) } & \multirow{2}{*}{$\begin{array}{r}\text { Rata- } \\
\text { rata }\end{array}$} \\
\hline & 2013 & 2014 & 2015 & 2016 & \\
\hline
\end{tabular}

\begin{tabular}{|c|c|c|c|c|c|}
\hline $\begin{array}{l}\text { Rumah } \\
\text { tangga }\end{array}$ & 3,8079 & 3,5309 & 3,9178 & 3,3504 & 2,8142 \\
\hline Sosial & 3,9411 & 4,3278 & 5,3598 & 5,4704 & 3,4072 \\
\hline Bisnis & 7,5159 & 10,1909 & 6,4204 & 11,6112 & 6,0318 \\
\hline Industri & 15,8784 & 31,4869 & 39,4678 & 28,2989 & 28,7830 \\
\hline Publik & 9,3548 & 5,6047 & 6,7039 & 20,4188 & 5,4159 \\
\hline \multicolumn{6}{|c|}{ Tabel 6. Intensitas Energi } \\
\hline \multirow{2}{*}{ Sektor } & \multicolumn{5}{|c|}{ Intensitas energi listrik (GWh/pelanggan) } \\
\hline & 2012 & 2013 & 2014 & 2015 & 2016 \\
\hline $\begin{array}{l}\text { Rumah } \\
\text { tangga }\end{array}$ & 0,0010 & 0,0010 & 0,0011 & 0,0011 & 0,0012 \\
\hline Sosial & 0,0028 & 0,0030 & 0,0030 & 0,0034 & 0,0040 \\
\hline Bisnis & 0,0024 & 0,0024 & 0,0033 & 0,0034 & 0,0032 \\
\hline Industri & 0,0536 & 0,0500 & 0,0436 & 0,0346 & 0,0294 \\
\hline Publik & 0,0492 & 0,0465 & 0,0444 & 0,0432 & 0,0395 \\
\hline
\end{tabular}

Tabel 7. Pertumbuhan Intensitas Energi

\begin{tabular}{crrrrr}
\hline \multirow{2}{*}{ Sektor } & \multicolumn{4}{c}{ Pertumbuhan intensitas energi (\%) } & Rata- \\
\cline { 2 - 5 } & 2013 & 2014 & \multicolumn{1}{c}{2015} & 2016 & rata \\
\hline Rumah & 0,6315 & 4,4550 & 5,4765 & 7,8142 & 4,5943 \\
tangga & & & & & \\
Sosial & 5,2157 & $-0,7344$ & 15,9379 & 14,7731 & 8,7981 \\
Bisnis & $-2,7099$ & 37,1543 & 3,4516 & $-5,6378$ & 8,0646 \\
Industri & $-6,7423$ & $-12,7273$ & $-20,6170$ & $-15,0953$ & $-13,7955$ \\
Publik & $-5,6002$ & $-4,3582$ & $-2,8637$ & $-8,4125$ & $-5,3087$ \\
\hline
\end{tabular}

\subsection{Desain Analisis Data pada LEAP}

Dalam perangkat lunak LEAP disediakan empat modul utama, yaitu modul variabel penggerak (driver variable module), modul permintaan (demand module), modul transformasi (transformation module), dan modul sumber daya energi (resources module). Oleh karena penelitian ini hanya menganalisis data untuk meramalkan kebutuhan energi listrik di masa depan, tanpa merencanakan upaya dan sumber pemasokan energinya, maka hanya dibutuhkan dua modul. Kedua modul tersebut adalah modul variabel penggerak (driver variable module) dan modul permintaan (demand module). 


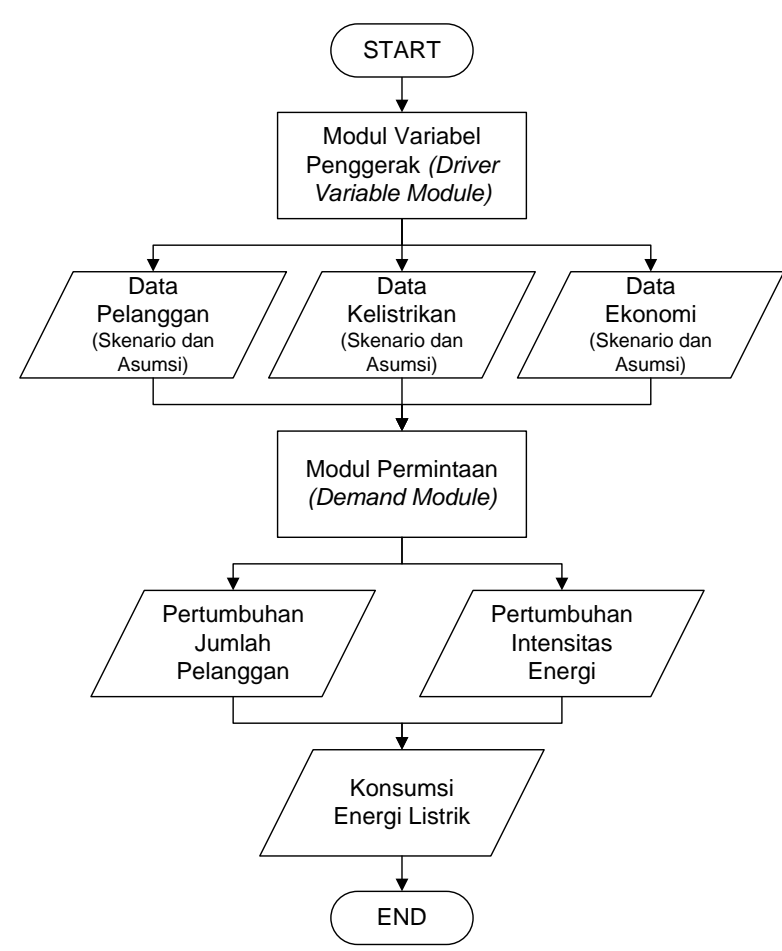

Gambar 2. Desain analisis data menggunakan perangkat lunak LEAP

Gambar 2 menyajikan desain analisis data yang direncanakan menggunakan perangkat lunak LEAP. Modul variabel penggerak berfungsi menampung parameter-parameter umum yang dapat digunakan pada modul permintaan nantinya. Parameter umum ini dapat berupa jumlah penduduk dan PDRB. Modul variabel penggerak ini bersifat komplemen terhadap modul lainnya.

Sedangkan modul permintaan berfungsi menghitung kebutuhan energi setiap sektor pemakai energi. Kebutuhan energi dihitung melalui perkalian antara aktifitas pemakaian energi (misalnya jumlah penduduk, jumlah kendaraan, volume nilai tambah, dan lain-lain) dengan intensitas pemakaian energi yang bersangkutan. Metode ini terdiri dari dua model analisis yaitu analisis permintaan energi final (final demand energy analisis) dan analisis permintaan energi terpakai (useful demand energy analisis). Penelitian ini menggunakan model analisis permintaan energi final.

\section{Hasil dan Pembahasan}

\subsection{Proyeksi Jumlah Pelanggan Energi Listrik}

Hasil analisis untuk peramalan proyeksi jumlah pelanggan energi listrik Kabupaten Bireuen pada tahun 2017 sampai dengan 2026 menggunakan perangkat lunak LEAP adalah seperti disajikan dalam Tabel 8. Proyeksi jumlah pelanggan energi listrik Kabupaten Bireuen menunjukkan akan adanya peningkatan dari tahun 2017 sampai dengan 2026. Dari total 119.782 pelanggan pada tahun 2017 akan menjadi 183.016 pelanggan pada tahun 2026. Dengan demikian pertumbuhan pelanggan dari tahun 2017 sampai dengan 2026 (selama 10 tahun) adalah sebesar 47,72 persen, dengan rata-rata pertumbuhan pelanggan adalah 4,7 persen per tahun.

Tabel 8. Proyeksi Jumlah Pelanggan Energi Listrik Kab. Bireuen

\begin{tabular}{lrrrrrr}
\hline \multirow{2}{*}{ Tahun } & \multicolumn{5}{c}{ Jumlah pelanggan tiap sektor } & \multirow{2}{*}{ Total } \\
\cline { 2 - 6 } & $\begin{array}{l}\text { Rumah } \\
\text { Tangga }\end{array}$ & Sosial & Bisnis & Industri & Publik & \\
\hline 2017 & 104.906 & 3.172 & 10.157 & 1.039 & 508 & 119.782 \\
2018 & 108.737 & 3.323 & 11.065 & 1.338 & 562 & 125.025 \\
2019 & 112.708 & 3.482 & 12.053 & 1.724 & 621 & 130.582 \\
2020 & 116.824 & 3.648 & 13.130 & 2.220 & 686 & 136.507 \\
2021 & 121.090 & 3.822 & 14.303 & 2.858 & 759 & 142.832 \\
2022 & 125.512 & 4.005 & 15.581 & 3.681 & 838 & 149.617 \\
2023 & 130.095 & 4.196 & 16.973 & 4.740 & 927 & 156.931 \\
2024 & 134.846 & 4.396 & 18.490 & 6.105 & 1.024 & 164.860 \\
2025 & 139.770 & 4.606 & 20.142 & 7.862 & 1.132 & 173.511 \\
2026 & 144.874 & 4.826 & 21.941 & 10.124 & 1.251 & 183.061 \\
\hline
\end{tabular}

\subsection{Proyeksi Konsumsi Energi Listrik}

Adapun proyeksi konsumsi energi listrik yang diramalkan menggunakan perangkat lunak LEAP disajikan dalam Tabel 9 dan visualiasinya ditampilkan pada Gambar 3. Hasil proyeksi konsumsi energi listrik Kabupaten Bireuen menunjukkan adanya peningkatan dari total konsumsi energi sebanyak 225,11 GWh pada tahun 2017 akan menjadi 563,02 GWh pada tahun 2026. Sehingga rata-rata pertumbuhan konsumsi energi listrik dari tahun 2017 sampai 2026 adalah sebesar 10,67 persen per tahun. Rata-rata konsumsi energi ini lebih tinggi dibandingkan dengan nilai rata-rata pertumbuhan konsumsi energi dari rentang waktu tahun 2012 sampai dengan 2016 (yaitu 9,67\%). 


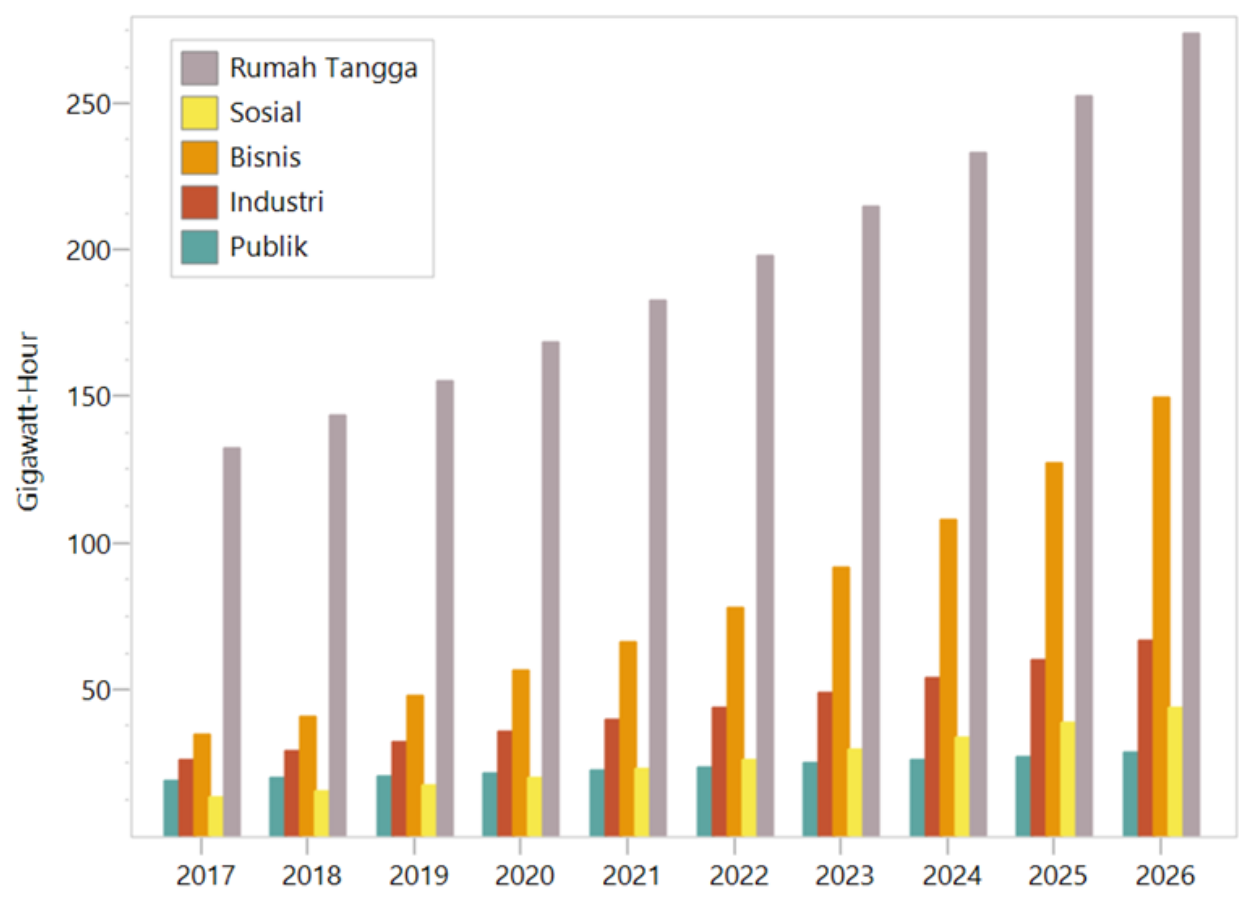

Gambar 3. Proyeksi Konsumsi Energi Listrik Kab. Bireuen

Tabel 9. Proyeksi Konsumsi Energi Listrik Kab. Bireuen

\begin{tabular}{|c|c|c|c|c|c|c|}
\hline \multirow[b]{2}{*}{ Tahun } & \multicolumn{5}{|c|}{ Konsumsi listrik tiap sektor (GWh) } & \multirow[b]{2}{*}{ Total } \\
\hline & $\begin{array}{l}\text { Rumah } \\
\text { Tangga }\end{array}$ & Sosial & Bisnis & Industri & Publik & \\
\hline 2017 & 132,29 & 13,47 & 34,49 & 26,04 & 18,81 & 225,11 \\
\hline 2018 & 143,44 & 15,36 & 40,61 & 28,91 & 19,69 & 248,01 \\
\hline 2019 & 155,54 & 17,51 & 47,82 & 32,10 & 20,61 & 273,57 \\
\hline 2020 & 168,65 & 19,96 & 56,30 & 35,64 & 21,57 & 302,12 \\
\hline 2021 & 182,87 & 22,76 & 66,28 & 39,57 & 22,58 & 334,06 \\
\hline 2022 & 198,28 & 25,95 & 78,04 & 43,94 & 23,63 & 369,84 \\
\hline 2023 & 215,00 & 29,58 & 91,88 & 48,78 & 24,74 & 409,98 \\
\hline 2024 & 233,12 & 33,73 & 108,18 & 54,16 & 25,89 & 455,08 \\
\hline 2025 & 252,77 & 38,45 & 127,37 & 60,14 & 27,10 & 505,83 \\
\hline 2026 & 274,08 & 43,84 & 149,96 & 66,77 & 28,36 & 563,02 \\
\hline
\end{tabular}

\subsection{Proyeksi Rasio Elektrifikasi}

Sementara itu, hasil proyeksi rasio elektrifikasi daerah Kabupaten Bireuen yang dianalisis menggunakan perangkat lunak LEAP adalah seperti ditunjukkan dalam Tabel 10. Rasio elektrifikasi Kabupaten Bireuen hampir mencapai nilai maksimal yaitu berkisar antara $98 \%$ sampai dengan 99\%. Hal tersebut menunjukkan bahwa hanya sekitar satu persen penduduk Kabupaten Bireuen belum terkoneksi dengan listrik.
Tabel 10. Proyeksi Rasio Elektrifikasi

\begin{tabular}{cc}
\multicolumn{2}{c}{ Kab. Bireuen } \\
\hline Tahun & $\begin{array}{c}\text { Rasio Elektrifikasi } \\
(\%)\end{array}$ \\
\hline 2017 & 98,87 \\
2018 & 98,93 \\
2019 & 98,99 \\
2020 & 99,05 \\
2021 & 99,11 \\
2022 & 99,18 \\
2023 & 99,24 \\
2024 & 99,30 \\
2025 & 99,36 \\
2026 & 99,42 \\
\hline
\end{tabular}

\subsection{Proyeksi Elastisitas Energi Listrik}

Hasil proyeksi elastisitas energi untuk Kabupaten Bireuen ditunjukkan oleh Tabel 11. Adapun nilai rata-rata elastisitas energi listrik adalah sebesar 0,64 . Ini sesuai dengan rasio nilai rata-rata angka pertumbuhan ekonomi (PDRB) sebesar 6,86 persen terhadap nilai rata-rata pertumbuhan konsumsi energi sebesar 10,72 persen. 
Tabel 11. Proyeksi Elastisitas Energi Listrik Kab. Bireuen

\begin{tabular}{cc}
\hline Tahun & Elastisitas Energi \\
\hline 2017 & 0,68 \\
2018 & 0,67 \\
2019 & 0,67 \\
2020 & 0,66 \\
2021 & 0,65 \\
2022 & 0,64 \\
2023 & 0,63 \\
2024 & 0,62 \\
2025 & 0,62 \\
2026 & 0,61 \\
\hline
\end{tabular}

Menurut analisis data yang sudah dilakukan, telah diperoleh prakiraan jumlah pelanggan dan kebutuhan energi listrik dalam wilayah Kabupaten Bireuen di masa mendatang sampai tahun 2016. Data ini dapat menjadi bahan pertimbangan penting bagi pemerintah dalam rangka merencanakan penyediaan energi di masa depan. Adapun sumber-sumber energi energi listriknya, di samping pasokan daya listrik dari PT PLN, dimungkinkan juga dari sumber-sumber energi alternatif lainnya. Di antara alternatifnya dapat berupa sumber energi terbarukan, seperti energi listrik dari sel surya [13] dan energi listrik dari energi listrik dari pengereman regeneratif sepeda motor [14].

\section{Kesimpulan}

Hasil analisis data menggunakan perangkat lunak LEAP untuk meramalkan perkembangan kebutuhan energi listrik di Kabupaten Bireuen untuk tahun 2017 sampai dengan tahun 2026 memberikan beberapa kesimpulan berikut ini. Jumlah pelanggan energi listrik sebanyak 119.782 pada tahun 2017 adalah akan meningkat menjadi 183.016 pelanggan pada tahun 2026 dengan ratarata pertumbuhan 4,7 persen per tahun. Konsumsi energi listrik sebesar 225,11 GWh pada tahun 2017 akan mengalami peningkatan terus-menerus menjadi 563,02 GWh pada tahun 2026, dengan rata-rata pertumbuhan sebesar 10,67 persen per tahun. Rasio elektrifikasi pada tahun 2026 akan mencapai 99,42 persen yang berarti bahwa kurang dari satu persen masyarakat Bireuen yang tidak menggunakan listrik. Elastisitas energi akan menurun terus dan mencapai angka 0,61 pada tahun 2026 yang berarti bahwa Kabupaten Bireuen cukup efisien dalam menggunakan energi listrik.

\section{Daftar Pustaka}

[1] R. K. Dewayana, Hermawan, and Karnoto, "Proyeksi Kebutuhan dan Penyediaan Energi Listrik di Jawa Tengah Menggunakan Perangkat Lunak LEAP," 2011. Available: http://eprints.undip.ac.id/25245/

[2] C. P. Putra, M. Tuegeh, H. Tumaliang, and L. S. Patras, "Analisa Pertumbuhan Beban Terhadap Ketersediaan Energi Listrik di Sistem Kelistrikan Sulawesi Selatan," Jurnal Teknik Elektro dan Komputer, vol. 3, no. 2, 2014.

[3] E. H. Tampubolon, H. Tumaliang, and M. S. Rumbayan, "Kajian Perencanaan Energi Listrik di Wilayah Kabupaten Sorong Menggunakan Perangkat Lunak LEAP," Jurnal Teknik Elektro dan Komputer, vol. 3, no. 2, 2014.

[4] BPS, Kabupaten Bireuen dalam Angka 2017. Bireuen: Badan Pusat Statistik (BPS) Kabupaten Bireuen, 2017.

[5] "Undang-Undang Republik Indonesia Nomor 30 Tahun 2009 Tentang Ketenagalistrikan,".

[6] D. Suswanto, Sistem Distribusi Tenaga Listrik: Jurusan Teknik Elektro Fakultas Teknik Universitas Negeri Padang, 2009.

[7] "LEAP Training Exercises," Stockhlom Environment Institute, Boston Center, 2005.

[8] ADB, Achieving Universal Electricity Access in Indonesia. Mandaluyong City, Philippines: Asian Development Bank, 2016.

[9] A. Aditya, E. Suryani, and R. A. Hendrawan, "Analysis of Electricity Demand to Increase the Electrification Ratio (Case Study: Madura Island)," in The 2nd International Seminar on Science and Technology, 2016.

[10] P. J. Burke and Z. Csereklyei, "Understanding the energy-GDP elasticity: A sectoral approach," CAMA Working Paper, no. 45, 2016.

[11] F. G. Adams and P. Miovic, "On relative fuel efficiency and the output elasticity of energy consumption in Western Europe," Journal of Industrial Economics, vol. 17, no. 1, pp. 41-56, 1968.

[12] Shimi S.L. and Reji B, "Elasticity of

https://doi.org/10.25077/jnte.v8n1.608.2019 http://jnte.ft.unand.ac.id/index.php/jnte/index 
Energy Consumption in India," International Journal of Research in Electrical \& Electronics Engineering, vol. 1, no. 2, pp. 19-24, 2013.

[13] N. Arumsari and F. A. Pamuji, "Peramalan Irradiance Cahaya Matahari pada Sel Surya untuk Memenuhi Kebutuhan Energi Listrik dengan Metode Support Vector Regression (SVR)," Jurnal Nasional Teknik Elektro, vol. 6, no. 1, pp. 18-24, Maret 2017.

[14] M. Latif, A. Valdesio, and M. Muharam, "Energi Listrik dari Pengereman Regeneratif Sepeda Motor dengan Menggunakan Dinamo Sepeda," Jurnal Nasional Teknik Elektro, vol. 7, no. 2, pp. 90-95, Juli 2018.

\section{Biodata Penulis}

Devi Sutri Insani, memperoleh gelar sarjana di Program Studi Teknik Elektro Universitas Malikussaleh pada tahun 2018.
Badriana, memperoleh gelar Sarjana Teknik dari Universitas Malikussaleh pada tahun 2003. Pendidikan tingkat magister diselesaikannya pada Universitas Gadjah Mada pada tahun 2012. Saat ini beliau bekerja sebagai dosen pada Jurusan Teknik Elektro, Fakultas Teknik, Universitas Malikussaleh sejak tahun 2003. Bidang penelitiannya meliputi sistem distribusi dan instalasi listrik.

Muhammad Daud, memperoleh gelar Sarjana Teknik dari Universitas Sumatera Utara pada tahun 2001. Pendidikan tingkat magister dan doktoral diselesaikannya pada Institut Teknologi Bandung masing-masing pada tahun 2006 dan 2012. Saat ini beliau bekerja sebagai dosen pada Jurusan Teknik Elektro, Fakultas Teknik, Universitas Malikussaleh sejak tahun 2002. Beliau juga anggota International Association of Engineers (IAENG). Bidang penelitiannya meliputi sistem komunikasi digital, sistem informasi, dan energi terbarukan. 